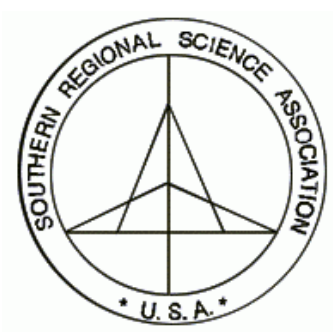

The Review of Regional Studies

Oklahoma State University

\title{
A Multi-Method Research Strategy for Understanding Change in the Rate of Working Poor in the North Central Region of the United States
}

\author{
Cynthia D. Anderson \\ Department of Sociology \& Anthropology, Ohio University, Athens, OH 45701, \\ email: andersc2@ohio.edu \\ W. Richard Goe \\ Department of Sociology, Anthropology \& Social Work, Kansas State University, \\ Manhattan, KS 66506-4003, email: goe@ksu.edu \\ Chih-Yuan Weng \\ Department of Sociology, Iowa State University, Ames, IA 50011-1070, \\ email: cyweng@iastate.edu
}

\begin{abstract}
Spatial statistics, econometric modeling, and other quantitative research methods provide the dominant approach to conducting research in regional science. This paper contends that a deeper understanding of many regional development processes can be gained by employing mixed method research designs that combine quantitative research methods with qualitative methods. This is illustrated through an analysis of change in the working poor in the North Central region of the U.S. during the post-1990 period. The findings from this paper combined with the subsequent paper by Loveridge et al. (2007) demonstrate that deeper insight into regional development processes can be gained by using mixed method research designs compared to quantitative designs alone.

Keywords: Working poor; Mixed methods; Sequential explanatory design; Comparative case study

JEL classification: I32; O18; R58

The authors contributed equally to the manuscript. This project $(\mathrm{NC1100)}$ was supported by the North Central Regional Association (NCRA) of Agricultural Experiment Station Directors by the Multi-state Research Fund (MRF,) which is a federal appropriation authorized by the Hatch Act. The authors wish to thank the editors and reviewers of the Review of Regional Studies for their helpful comments as well as support from Cornelia Flora, Linda Lobao, and Scott Loveridge.
\end{abstract}




\section{INTRODUCTION AND RATIONALE}

During the first decade of the twenty-first century, the quality of life in nonmetropolitan communities located in the North Central region of the United States is being seriously challenged by dramatic changes in government programs and processes of economic restructuring (Falk and Lobao 2003; Walzer 2003). ${ }^{1}$ Devolution of responsibility for the delivery of public goods and services has elevated the responsibilities of local governments in nonmetropolitan communities (Dewees, Lobao, and Swanson 2003; Lobao and Hooks 2003). The economies of many nonmetropolitan communities have undergone structural change due to globalization, which has presented both opportunities and threats to their economic well-being and quality of life. On the one hand, the expansion of global markets provides opportunities for the growth of local businesses. On the other hand, globalization may also mean the loss of local jobs due to outsourcing or business relocation and the suppression of local wages due to global competition in labor markets. More and more nonmetropolitan residents must engage in multiple jobs, often without benefits that came from the old economy.

The effects of globalization processes have been very uneven across nonmetropolitan communities in the U.S., including the North Central region. Some nonmetropolitan communities have been able to effectively respond to these changes and elevate their quality of life by developing industries that provide high-skill jobs and increase the incomes of local workers. In contrast, other nonmetropolitan communities have been less fortunate and have experienced sharp increases in low-wage employment and the number of working poor (Anderson, Schulman, and Wood 2001; Lobao, Hooks, and Tickamyer 2007). In effort to better understand the uneven distribution of change in the working poor population, researchers must consider issues of spatial inequality. Theoretically informed research designs need to be flexible enough to address questions of how and why socially valued resources are differentially allocated across the region.

In 1998, 67.3 percent of nonmetropolitan poor families had at least one member of the household holding at least one job (Gibbs and Parker 2001). These individuals spent at least 27 weeks in the labor force, but their family incomes fell below the official poverty threshold. This data suggests that there are a substantial number of jobs in nonmetropolitan America that pay low wages, offer few benefits, or are part-time or contingent employment. Within the North Central region, we found that women, young people, and people of color were more likely than men to be working and poor in 2000 . The region also exhibited higher-than-average rates of working poor for whites and persons with advanced education compared to the U.S. as a whole. In addition, the working poor population was unequally distributed across the region (Anderson and Weng 2006a; 2006b). These findings imply that the processes of inequality that produce the working

\footnotetext{
${ }^{1}$ For the purposes of this study, the North Central region consists of the following states: Illinois, Indiana, Iowa, Kansas, Michigan, Minnesota, Missouri, Nebraska, North Dakota, Ohio, South Dakota, and Wisconsin.
} 
poor population do not apply uniformly across nonmetropolitan areas within the region. Some places have been able to effectively ameliorate this problem, while it has been exacerbated in others.

The key purpose of this paper is to describe how research designs employing "mixed methods" (i.e., a combination of both quantitative and qualitative methodologies) may be useful as a means of obtaining deeper insight into processes of regional development that cannot be derived through a single methodological approach. This will be illustrated with an analysis of change in the working poor population. First we estimate a linear panel model with lagged effects to examine the effects of labor market attributes, demographic characteristics, and rurality on change in the rate of working poor within the North Central region during the 1990-2000 period. While the results of our model demonstrate the relevancy of these factors and explain a substantial portion of the variation in the change in the rate of working poor across the region, the model results can only indirectly address the complex reasons why those changes have occurred. What is not known is the myriad of ways structural disadvantages may be countered by the agency of local communities, including economic policies and social programs aimed at raising different forms of community capital (human, social, and cultural) and reducing poverty from lowpaying jobs.

We fully recognize the particular strengths of econometric analysis such as the ability to mathematically estimate the effects of independent variables, identify the functional form of statistical relationships, and draw empirical generalizations with a known probability of inaccuracy. However, it is our contention that many types of essential information that help illuminate regional change processes are best obtained through qualitative research designs employing case studies of specific regions or communities. While a growing body of scholarship exists that employs the latter approach (see, for example, Falk, Schulman, and Tickamyer 2003), a key challenge is the selection of genuinely comparable cases. To be generalizable, the cases selected must lend themselves to systematic cross-case analysis while still providing intensive within-case analysis. To this end, we advocate a mixed method, sequential explanatory research design (Creswell et al. 2002).

Our research design involves: 1) linear panel analysis of county-level data, 2 ) systematic selection of outlier counties to serve as sites for community case studies, and 3) coordinated case studies of communities within these counties by a team of researchers. The results of the case studies are discussed in a subsequent paper by Loveridge et al. (2007). By combining the results obtained in our research with the case analyses presented in the Loveridge et al. (2007) paper, an understanding of unmeasured policies and action strategies that affect the prevalence of the working poor at the community level can be gained, as can a deeper understanding of the processes underlying the statistical relationships found in the panel model.

The remainder of the paper is ordered as follows: the second section of the paper reviews literature that is pertinent to this research. The third section presents the model 
specification and results of the linear panel analysis designed to explain the variation in change in the working poor rate across counties in the North Central region during the 1990-2000 period. The fourth section describes how the results of the panel analysis were used to select nonmetropolitan counties as case study sites. This is followed by discussion and conclusions.

\section{LITERATURE REVIEW}

Two distinct sets of literature inform our research. First, we examine factors influencing the size of the working poor population in general and the nonmetropolitan working poor within the North Central region (i.e., the midwest) in particular. From this, we contend that the working poor population within a nonmetropolitan area is influenced by the attributes of local labor markets, demographic characteristics of the local population, and community-level characteristics and government policies designed to alleviate poverty and promote economic development. Second, we examine the literature on mixed method research designs that combine quantitative and qualitative methodologies. As noted above, it is our contention that the effects of a number of these factors, particularly those at the community level, cannot be easily examined by econometric models estimated from secondary data sources. Therefore, a research design employing a mixed methods approach will be more effective in examining the effects of processes for which data are not readily available and/or may not be easily measured. To this end, we advocate a sequential explanatory research design to offset the weaknesses of econometric modeling.

\subsection{Factors Affecting the Working Poor in the North Central Region}

Within the context of a market economy, the concept of "working poor" is based on the level of income that is socially defined as adequate for the sustenance of families or other social units. The procurement of sustenance by the human population is most typically organized at the level of the household (which may be a family or nonfamily household using the categories of the U.S. Census Bureau) whose members must earn an income in order to purchase their means of sustenance through the market. Simply put, members of households become working poor when one or more members are able to sell their labor power in the local labor market but, due to specific conditions, are unable to secure wages that are above the poverty threshold in exchange and cannot obtain sufficient income from other sources to raise their incomes above this level (Goe and Rhea 2000). Thus, the local labor market is a central institution influencing the size of the working poor population within a region or community.

The distinct economic history of the North Central region of the United States makes the labor markets within it unique from other areas of the country. In this region, agriculture became most extensively characterized by "family farming" involving familyowned farms engaged in the commercial production of grain and livestock (Pfeffer 1983). Further, as industrialization progressed in the United States, the region served as a location for important areas of the old "manufacturing belt" (Scott 1988). Page and 
Walker (1991) noted the dynamic relationship between these two sectors of the regional economy as family farmers and nonmetropolitan communities were highly connected to industrial employment. Family farmers served as a large market for the machinery, equipment, and home goods produced by rural as well as urban manufacturers. Page and Walker (1991) argued that this region served as a cradle of U.S. Fordism, distinct in its development from the northeastern manufacturing belt where farmers and rural communities played a less important role. While there are some studies of states in the region, the North Central region as a whole remains relatively little studied as a regional unit with a distinct social ecology and political-economic history.

Reflecting broader macro-economic trends, the farming sector within the region underwent decline over much of the twentieth century with regard to the number of farming enterprises and the number of jobs provided by farming. Improvements in farm mechanization (first as a result of the internal combustion engine and later as a result of the application of information technology) and the development of hybrid seeds and petrochemicals permitted prodigious increases in farm productivity (Kenny et al. 1989). These ongoing technological improvements eventually allowed a single farm operator to cultivate thousands of acres of land. This capacity, combined with the physical demands of farming, the financial risk involved in the business (producing farm foreclosures), and the aging and retirement of the farm population have all contributed to the decline in the number of farms and farm employment within the region as on-going consolidation furthers the structural trend toward fewer but larger farm enterprises at the upper end, combined with a tier of small, part-time, and/or niche farms at the lower end.

While farming continues to provide an important source of income for many nonmetropolitan communities within the North Central region, it has become less important. Further, farming has long ceased to provide a source of new full-time jobs for the nonmetropolitan labor force. While the production of some farm commodities within the region continues to be labor intensive, such labor needs are primarily met through hiring part-time, seasonal workers. Thus, we hypothesize that the maintenance of higher levels of dependency on agriculture for employment would increase the number of working poor in nonmetropolitan communities through directly providing low-wage, contingent employment. Further, the development of part-time farming would create a labor supply more readily accepting of low-wage work to supplement farm incomes.

The deindustrialization movement in the U.S. (Bluestone and Harrison 1982), which accelerated during the 1970s and 1980s, has had severe economic consequences for the North Central region. Industrial-based metropolitan areas within the region (e.g., Detroit, Cleveland, Chicago) experienced severe losses of manufacturing jobs (see, for example, Goe and Shanahan 1991), which continue today. During the 1970s, this worked to the benefit of nonmetropolitan areas in the U.S. as it furthered the decentralization of factory work away from urban centers to nonmetropolitan communities (see, for example, Summers 1976). As with the broader macro economy, manufacturing employment also declined in nonmetropolitan areas during the 1980s. However, with the economic growth 
of the 1990s, nonmetropolitan manufacturing employment expanded again (Kandel 2006).

In the post-1990 period, the effects of globalization on nonmetropolitan manufacturing were unevenly felt. The globalization movement led to deindustrialization in some nonmetropolitan communities as manufacturing work continues to be shifted offshore (see, for example, Lobao, Brown, and Moore 2003). However, reflecting the broader nonmetropolitan growth trend, a substantial number of nonmetropolitan communities have successfully retained and/or attracted new industry as manufacturing work continues to be decentralized from older industrial cities and globalization promotes foreign investment in manufacturing capacity in the U.S. For example, the beef processing industry has expanded in nonmetropolitan areas of the North Central region (Kandel 2006). Further, the recent movement to develop alternative fuels has resulted in the rapid construction of ethanol bio-refineries in nonmetropolitan communities within the region (Barrett 2007). Having a higher dependence on manufacturing for employment would logically contribute toward reducing the size of the working poor population through the provision of jobs that pay higher wages.

Also reflecting broader macroeconomic trends, the vast majority of nonmetropolitan workers within the region are now employed in service sector industries. It is important to emphasize that the service sector includes a substantial number of jobs that pay high salaries (e.g., doctors, business consultants, lawyers). However, the vast majority are lower-level, service provision jobs that pay lower wages; many are contingent (e.g., retail sales clerks, bank tellers). It has been found that jobs in nonmetropolitan manufacturing industries pay higher wages than jobs in nonmetropolitan service sector industries (Gibbs, Kusmin, and Cromartie 2005). Having a strong dependence on service sector industries for employment would likely contribute to increasing the size of the working poor population through the provision of low-wage and/or contingent jobs. On the other hand, government employment, which is frequently viewed as part of the service sector, has been found to be associated with higher median family incomes and lower income inequality over time (Lobao and Hooks 2003). Thus, strong dependence on government employment would likely contribute to decreasing the size of the working poor population.

Economic restructuring generally assumes fundamental social alterations that foster new forms and patterns of inequality, generating a dramatic increase in low-skilled, poorly paid jobs. Gibbs, Kusmin, and Cromartie (2005) challenged this assertion, noting that the impacts of new patterns vary across place and outcomes for members of nonmetropolitan communities vary. Different types of industries, firms, and jobs result in different levels of economic growth and also affect the degree to which benefits of growth are distributed. Thus, as noted above, the size of the working poor population within a nonmetropolitan community is influenced by the particular industry mix and the particular firms that comprise the demand side of the local labor market. 
Supply-side characteristics of a local labor market are also important in influencing the size of the working poor population. Acquiring education (i.e., developing human capital) has long been touted as a means of upper mobility and avoiding poverty (Becker 1964; Blau and Duncan 1967). Thus, communities with a highly educated workforce would be more likely to exhibit fewer working poor. Further, particular segments of the labor force (e.g., women, minorities, young adults, and elderly workers) have been found to be more vulnerable to accepting low-wage employment and becoming working poor (e.g., Jensen and Slack 2003; Rank 2004; United States Department of Labor 2002).

Finally, the demographic characteristics of a community, such as the prevalence of specific household types, have been found to be linked to the size of the working poor population. For example, in 1990, single-parent family households headed by employed females were found to be five times more likely to be working poor compared to married-couple family households with the head and/or spouse employed (Goe and Rhea 2000). Elderly households, particularly those that do not require employment to earn sufficient incomes as a result of wealth or income from other sources, would logically influence the working poor population by reducing the size of the elderly component of the labor force vulnerable to accepting low-wage employment and by the re-circulation of their wealth through the local economy, thereby elevating the possibility of higherwage employment within the local labor market.

It is important to note that the North Central region encompasses a diversity of human communities ranging from large metropolitan areas with millions in population to nonmetropolitan areas with small cities (i.e., now called micropolitan areas) to remote rural areas with very small populations. We employ the term "spatial context" to describe these differences. We expect that communities located in a rural spatial context are more likely to have a higher relative prevalence of working poor because they are more likely to encompass low-wage labor markets as a function of a lower cost of living, have smaller labor forces, and have greater isolation from labor movements that tend to be concentrated in urban areas.

No matter what the size of the community involved, it is our contention that community-level factors are also likely to be important in influencing the local prevalence of working poor. Communities could develop the capacity to influence the local prevalence of working poor in a number of important ways. First, community-level economic policies may influence the particular mix of industries and firms that locate there as well as the types of jobs that are available within the local labor market. For example, assuming that other factors of production are viewed as more important than wage rates in influencing the decisions of firms to locate within a particular community, a living wage policy could help reduce the size of the working poor population. Unique economic development policies may help attract industries and firms that pay higher wages. Local training programs or entrepreneurial programs may imbue the labor force with specific skills that ultimately lead to the growth of higher-wage jobs. 
It has been hypothesized that the levels and types of social capital present within a community are important in influencing the type of economic development that may occur. Social capital reflects the connections among people and organizations or the social "glue" that make things happen within a community (see Portes and Sensenbrenner 1993; Coleman 1993; Putnam 2000; Schulman and Anderson 1999). Bonding social capital refers to those close redundant ties that build community cohesion. Bridging social capital involves loose ties that bridge diverse groups and organizations within the community as well as link the community to the external social milieu (Granovetter 1973; Woolcock 1998). Logically, the presence of both types of social capital within a community could have important influences on the prevalence of the working poor. For example, the levels and types of bridging social capital could be very important in terms of industrial recruitment; obtaining financial resources; or participating in federal, state, or regional economic development programs.

In sum, our theoretical framework views the working poor population within a given geographic area as a function of labor market, household, and community-level conditions and processes. Examining the role of community-level conditions and processes is particularly problematic using quantitative methodology and econometric modeling. One key reason is that measures of these variables are not readily available for all communities within large regions or the nation. Another reason is that community-level phenomenon such as the extent of different types of social capital are not easily measured. It is our contention that the effects of variables that are difficult to measure and incorporate into econometric models may be better examined through the use of mixed method research designs employing both quantitative and qualitative methodologies. In addition, such designs may better illuminate and provide a deeper understanding of the processes underlying the statistical relationships found in an econometric model.

\subsection{Mixed Method Research Designs}

According to Creswell and Plano Clark (2007), mixed methods research involves collecting and analyzing both quantitative and qualitative data. By mixing datasets, the researcher is able to provide a more adequate understanding of the problem than if either dataset had been used alone. Data from the distinct datasets can be merged, connected, or embedded. To be credible, the mixed methods design must maintain methodological congruence and adhere to all of the assumptions of the methods, using consistent methodological components (Morse 2002).

Creswell et al. (2002) specify six different types of major mixed methods designs: ${ }^{2}$ sequential explanatory, sequential exploratory, sequential transformative, concurrent

2 The six major designs offered by Creswell et al. (2002) are based on four criteria: the implementation or sequence that is used to collect both quantitative and qualitative data, the priority given to quantitative and qualitative research as it occurs through the data collection process, the stage of the research process at which integration of quantitative and qualitative data collection takes place, and the theoretical perspective that guides the research. 
triangulation, concurrent nested, and concurrent transformative. Our design is most aligned with the sequential explanatory design, containing two distinct data collection phases, one following the other. The purpose of sequential explanatory design is to use qualitative results to assist in the interpretation of quantitative findings and provide a deeper understanding of the statistical relationships observed. As Morse (1991) notes, a sequential explanatory design can be especially useful when unexpected results arise from quantitative modeling.

For example, in the initial stage of this research, we first used readily available quantitative data to estimate a linear panel model that examined the effects of labor market attributes, demographic characteristics, and spatial context (i.e., rurality) on change in the rate of working poor across counties in the North Central region during the 1990-2000 period. We then used the results of the estimated model to create a sample of counties characterized by "unexpected results," that is, counties that represent extreme outliers in the distribution of residuals. These extreme outliers were comprised of two groups: (a) counties that had a much greater decrease in their rate of working poor than predicted by the model; and (b) counties that had a much greater increase than predicted. As will be described in more detail below, a set of counties from each of these groups was selected for comparative case studies.

In the second stage of this research, in-depth case studies were completed on the selected counties using qualitative methods. For each case study, data was collected using some combination of: (a) personal observation; (b) personal interviews with local governments, economic development agencies, civic organizations, business owners, and workers in the local labor market; (c) content analysis of local newspapers, government documents, and other information sources; and where resources were available (d) survey research. The key purpose was to identify and gain an understanding of the processes that produced a greater-than-predicted increase or decrease in the rate of working poor, including the role of community agency (i.e., local economic development policies, social capital, etc.). A second purpose was to gain a deeper understanding of the processes underlying the significant relationships found in the quantitative model.

In sum, not only does a sequential explanatory design allow researchers to develop a more comprehensive understanding of the phenomenon being studied compared to using a quantitative or qualitative approach alone (Morse 2002), it also permits researchers to obtain different levels of data. The use of distinct phases facilitates its implementation, description, and sharing of results. Figure 1 offers a visual diagram of the sequential explanatory design we employed. 


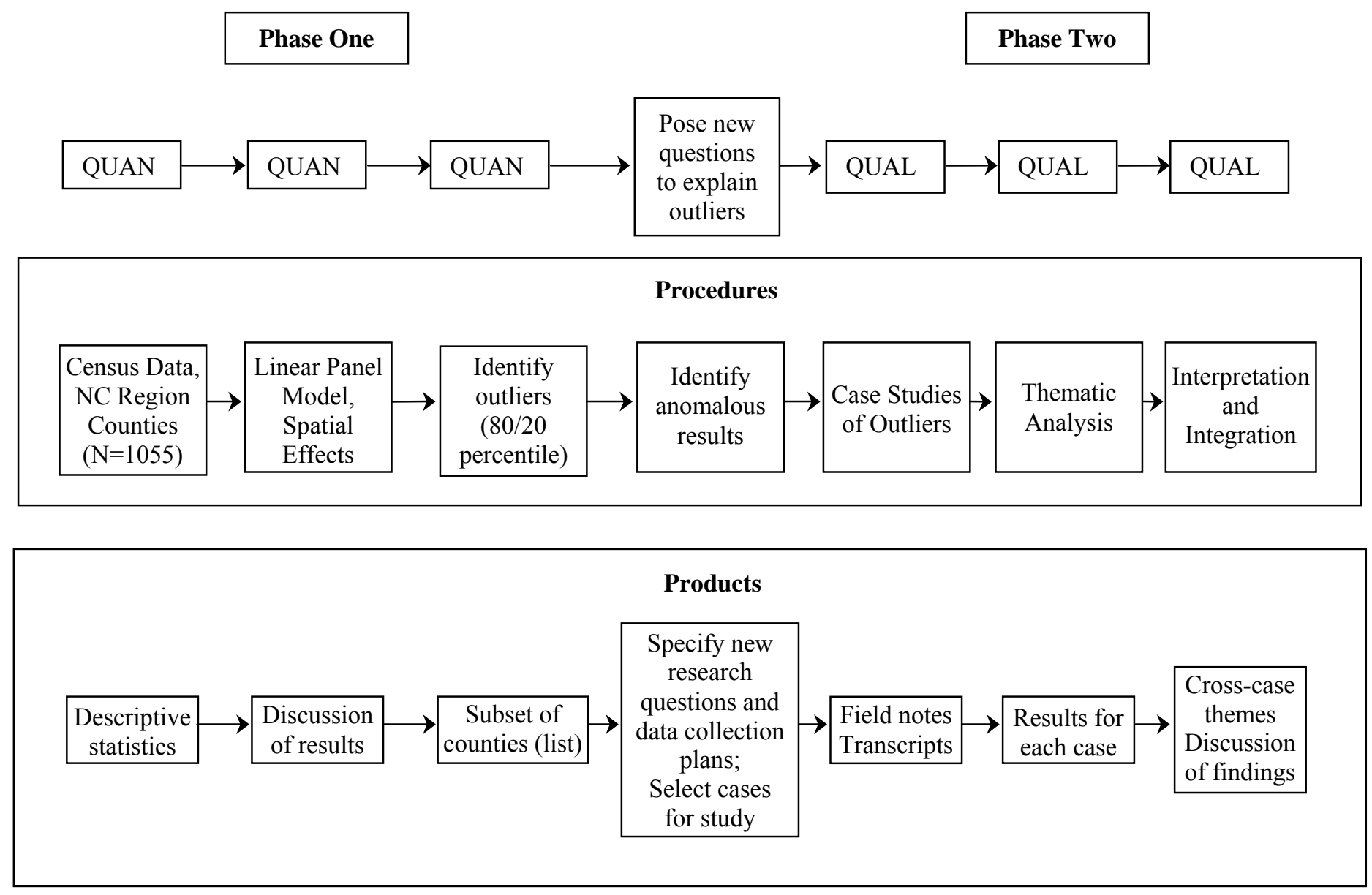

FIGURE 1. Sequential Explanatory Design

(Based on Visual Diagram Provided by Cresswell and Plano Clark, 2007, p. 51) 


\section{PHASE ONE IN THE SEQUENTIAL EXPLANATORY DESIGN: DATA AND METHODS}

In phase one of our research, a panel data set was constructed using measures drawn from a number of databases collected by the U.S. government, including the U.S. Census of Population and Housing $(1993,2003)$ and the Rural Urban Continuum Codes developed by the Economic Research Service of the United States Department of Agriculture (2003). Data were collected for all 1,055 counties that comprise the 12 states in the North Central region. The rate of working poor was measured as the percent of households with incomes below the poverty threshold while at least one household member was employed. Figure 2 displays working poor rates for all counties within the region for 2000. This rate ranged from approximately 2.2 percent in Ozaukee County, Wisconsin, to 34.5 percent in Athens County, Ohio. This map illustrates the spatial inequality in working poor rates across the counties of the region. Further, it reveals that counties with high rates of working poor in 2000 were clustered together within the geographic space of the region, particularly in southern Ohio, southern Missouri, and select areas of North and South Dakota.

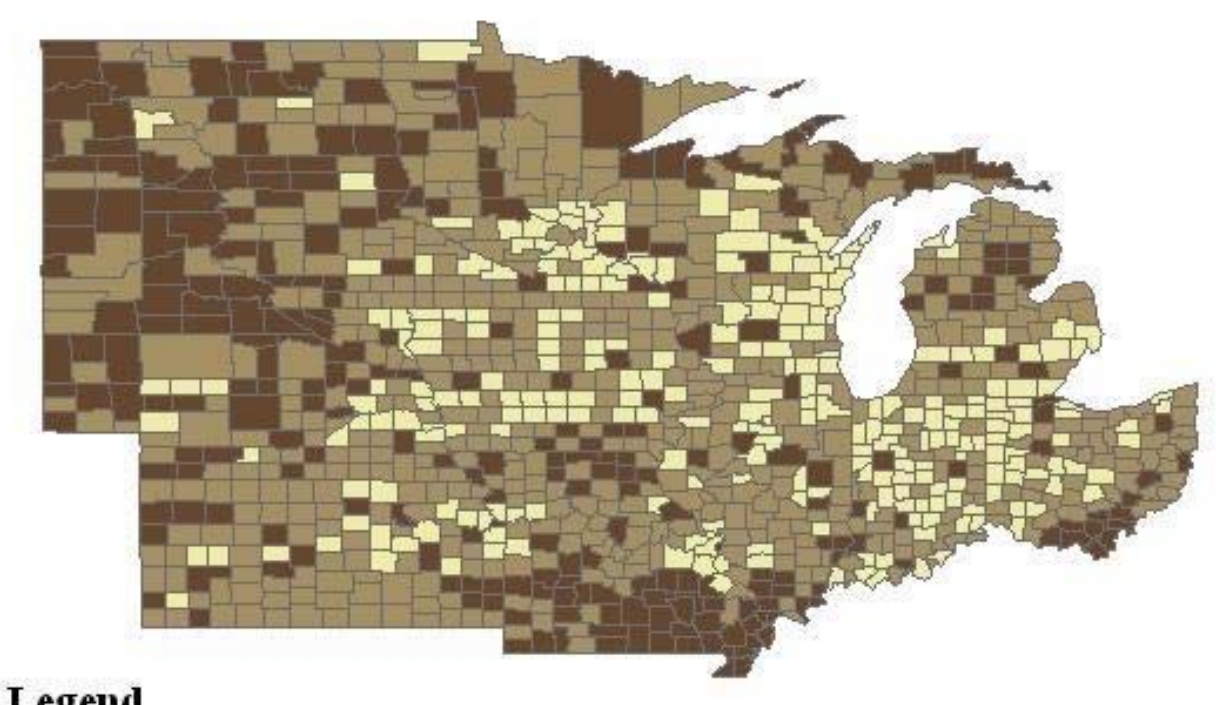

\section{Legend}

Low (below 25th percentile: $2.2187-6.4332 \%$ )

Moderate (between 25th and 75th percentile: 6.4333 - 10.3301\%)

High (above 75 th percentile: $10.3302-34.5053 \%$ )

FIGURE 2. Uneven Rates of Working Poor Across the North Central Region (2000) 
The next step in phase one was to use linear panel analysis to identify factors and conditions associated with changes in the rate of working poor across the 1,055 counties in the region for the 1990-2000 period. After modeling changes in the rate of working poor, we used the outputs to identify nonmetropolitan outlier counties that experienced larger increases or decreases than predicted by the panel model. These outlier counties formed two subsets of nonmetropolitan counties representing the extremes in the spatial distribution of change in the rate of working poor within the region. Counties that would serve as case study sites were then selected for Phase Two of our research - the systematic and coordinated analysis of case studies. As noted above, the results of these case studies are described in a subsequent paper by Loveridge et al. (2007). The combined results of our mixed method sequential explanatory design explicate the relationships found in the panel analysis at a deeper level and provide insight into community-level factors that influenced changes in the rate of working poor within the region.

\subsection{Linear Panel Model}

A linear panel model was estimated for the 1990-2000 period to explain the variation in the change in the rate of working poor across the 1,055 counties that comprise the study region. The following model specification was used.

$$
Y_{[2000]}=\alpha+\left(\beta_{1} * Y_{[1990]}\right)+\sum_{i=1}^{k}\left(\beta_{i+1} * X_{i[1990]}\right)+\varepsilon_{[2000]}
$$

With this model specification, the rate of working poor in 2000 was regressed on the rate of working poor in 1990 and a vector of variables measuring spatial context, labor market attributes, and demographic characteristics measured in 1990 that were identified by our theoretical framework as relevant in influencing the prevalence of the working poor. (See Table 1 for description of these indicators and their means and standard deviations). By controlling for the rate of working poor in 1990, we were able to examine the relationship between base-line county characteristics in 1990 and the subsequent change in the rate of working poor that occurred over the 1990-2000 period. A series of block models were used to examine the pattern of change in effects that occurred as different categories of variables were introduced and statistically controlled. As a result of the likelihood of spatial interdependencies in the data, the model was also tested for spatial effects.

\subsection{Tests for Spatial Effects}

As has been extensively reviewed in Anselin (1988, 2001), inefficient or biased estimates and misleading inferences are inevitable when cross-sectional data involving geographic units are analyzed without taking into account such an issue as spatial dependence/autocorrelation. Specifically, two possible reasons are accountable for the observed spatial dependence/autocorrelation. On the one hand, measurement error in data associated with spatial units may result from a "scale-mismatch" where the administrative boundaries of data collection do not correspond to the true geographic nature of 
TABLE 1

Univariate Statistics and Measurement of Variables

\begin{tabular}{|c|c|c|c|c|c|c|}
\hline Variable Name & Range & Min. & Max. & Mean & $\begin{array}{c}\text { Std. } \\
\text { Deviation }\end{array}$ & Description of Indicator \\
\hline \%Poverty00 & 32.29 & 22.22 & 34.51 & 8.99 & 4.22 & $\begin{array}{l}\% \text { households with at least one employed person } \\
\text { and incomes below poverty threshold, } 2000\end{array}$ \\
\hline Spatial Lag & 18.41 & 3.62 & 22.03 & 9.05 & 2.64 & First-order queen-based spatial lag matrix \\
\hline \%Poverty90 & 35.03 & 2.15 & 37.18 & 10.97 & 4.77 & $\begin{array}{l}\% \text { households with at least one employed person } \\
\text { and incomes below poverty threshold, } 1990\end{array}$ \\
\hline Rurality & 8.00 & 1.00 & 9.00 & 6.11 & 2.55 & $\begin{array}{l}\text { ERS Beale Code, } 1993 \text {, ranging from } 0-9 . \text { The } \\
\text { greater the number, the more rural the county. }\end{array}$ \\
\hline \multicolumn{7}{|c|}{ Employment Mix by Industry } \\
\hline$\% \mathrm{Ag} / \mathrm{Mining}$ & 70.01 & 0.55 & 70.56 & 12.72 & 10.56 & $\begin{array}{l}\% \text { of employment in agriculture/mining industry } \\
\text { per county, } 1990\end{array}$ \\
\hline$\%$ Manufacture & 47.08 & 0.47 & 47.55 & 18.04 & 9.70 & $\begin{array}{l}\% \text { of employment in manufacturing industry per } \\
\text { county, } 1990\end{array}$ \\
\hline$\%$ Construction & 14.07 & 1.41 & 15.48 & 5.82 & 1.57 & $\begin{array}{l}\% \text { of employment in construction industry per } \\
\text { county, } 1990\end{array}$ \\
\hline$\%$ Service & 42.90 & 13.79 & 56.69 & 28.91 & 5.11 & $\begin{array}{l}\text { \% of employment in service industry per county, } \\
1990\end{array}$ \\
\hline \%Government & 51.79 & 6.64 & 58.42 & 15.11 & 5.87 & $\begin{array}{l}\% \text { of employment in government industry per } \\
\text { county, } 1990\end{array}$ \\
\hline \multicolumn{7}{|c|}{ Labor Force and Demographic Composition } \\
\hline$\%$ Female Labor & 17.18 & 32.87 & 50.05 & 44.07 & 2.14 & $\%$ labor force comprised of female workers, 1990 \\
\hline$\%$ Nonwhite Labor & 90.69 & 0.00 & 90.69 & 3.54 & 7.62 & $\%$ labor force comprised of minorities, 1990 \\
\hline$\%$ Young Labor & 36.23 & 4.56 & 40.79 & 15.59 & 4.09 & $\%$ labor force between 16-24 years of age, 1990 \\
\hline$\%$ Elderly Labor & 27.49 & 6.15 & 33.64 & 16.10 & 4.46 & $\%$ labor force 55 years of age and over, 1990 \\
\hline $\begin{array}{l}\% \text { Female Head of } \\
\text { Household }\end{array}$ & 41.31 & 8.59 & 49.90 & 26.14 & 4.14 & \% households headed by females, 1990 \\
\hline $\begin{array}{l}\text { \%Elderly Head of } \\
\text { Household }\end{array}$ & 37.04 & 8.47 & 45.51 & 28.22 & 6.32 & $\begin{array}{l}\% \text { households headed by elderly persons } 65 \text { years } \\
\text { of age and over, } 1990\end{array}$ \\
\hline$\%$ College Labor & 37.35 & 2.86 & 40.21 & 13.24 & 4.73 & $\begin{array}{l}\% \text { working-age population } 18-65 \text { years of age } \\
\text { with a college degree, } 1990\end{array}$ \\
\hline
\end{tabular}


underlying data-generating processes. On the other, spatial components may be simply an indispensable aspect of the theoretical specification or modeling given a genuine spatial interaction at work among the variables or phenomena of interest. As a result, the linear panel model described in the previous section may not exempt itself from a misspecification error due to spatial dependence/autocorrelation if the geographic dimension of the census data under use is left thoroughly unattended.

More importantly, a proper alternative specification needs to be determined if spatial dependence/autocorrelation is detected. Past research has proposed two approaches to modeling spatial dependence/autocorrelation, contingent on its possible sources (Anselin 1988; Anselin and Bera 1998; Baller et al. 2001). First of all, the spatial error or the spillover effect is characterized by the correlated error terms across different spatial units, thus violating the OLS assumption of uncorrelated error terms. By ignoring unmeasured (and spatially correlated) independent variables, the obtained estimates, though unbiased, are conceivably inefficient and the inference could be misleading. The spatial disturbance (Land and Deane 1992) or spatial error (Anselin and Bera 1998; Baller et al. 2001) model, therefore, incorporates the spatial dependence into the error structure so that the error covariances are non-zero, i.e., $E\left[e_{i}, e_{j}\right] \neq 0$. More specifically, the resulting error structure implied by the spatial process is defined ad hoc and $a$ priori by a spatial weights matrix $W$.

The spatial lag effect, in contrast, is not simply an artifact of geographic patterning of measured and unmeasured independent variables. Instead, it is more compatible with the notion of diffusion process where events in one place actually increase the likelihood of their counterparts in neighboring places, above and beyond the effect of structural covariates. Stated more technically, a spatial lag effect suggests that dependent variable $y$ in place $i$ is predicted by the independent variables in both place $i$ and $j$. It is apparent that both assumptions of uncorrelated error terms and independent observations are violated with a spatial lag effect in OLS regression, leaving the estimates biased and inefficient. The spatial effect (Land and Deane 1992) or spatial lag (Anselin and Bera 1998; Baller et al. 2001) model, consequently, accounts for spatial dependence by including a serially autoregressive term, a so-called spatial lag covariate, which also involves a specific spatial weights matrix $W$ to capture the adjacency patterns of spatial units.

With an attempt to facilitating the spatial data analysis in social sciences in general, Anselin and colleagues (Anselin, Syabri, and Kho 2004; Anselin 2005) developed a free program called GeoDa that can be downloaded from www.geoda.uiuc.edu/ and provides user-friendly and graphic interface to methods of both descriptive spatial data analysis and spatial regression functionality. With regard to the latter, GeoDa provides an array of diagnostics that can help distinguish between two sources of spatial dependence/autocorrelation and choose accordingly a proper alternative model specification. In addition, unbiased regression estimates derived with a maximum likelihood approach are also available in GeoDa for both spatial lag and spatial error models. 
Following the "Spatial Regression Model Selection Decision Rule" (Anselin 2005, p. 198), we began estimating a spatially adjusted linear model by first estimating a classic OLS regression based on our original specification from the previous section and simultaneously testing for spatial dependence/autocorrelation based on a rook-based spatial weights matrix that defines as neighbors any location sharing a common border. The output showed that Moran's I score was positive (4.66) and highly significant $(p<.00001)$, thus suggestive of strong spatial dependence/autocorrelation of the residuals. Next, four diagnostics statistics are of particular importance, including Lagrange Multiplier (lag) (i.e., simple LM test for the lack of a spatially lagged dependent variable), Lagrange Multiplier (error) (i.e., simple LM test for error dependence), Robust LM (lag) (i.e., robust test for the lack of a spatially lagged dependent variable in the possible presence of error dependence), and Robust LM (error) (i.e., robust test for error dependence accompanied by the possible lack of a spatially lagged dependent variable). If the Lagrange Multiplier (lag) is significant but the Lagrange Multiplier (error) is not, it is indicative of a spatial lag effect at work. If the reverse is true, a spatial error effect is then identified. For this current study, we noted that both simple LM tests were significant, in which case we had to turn to the robust versions for further clarification. In essence, the output revealed that Robust LM (lag) but not Robust LM (error) was significant, suggesting that a spatial lag specification should be subsequently estimated.

After identifying what type of spatial dependence/autocorrelation was present, we then used GeoDa to re-estimate the model with a maximum likelihood approach while controlling for the spatial dependence/autocorrelation. Despite a positive and significant spatial lag term, parameters estimated by spatial lag regression were not qualitatively different from those estimated by OLS regression in terms of direction of correlation and level of significance. Specifically, all coefficients estimated from the spatial lag regression still had the same signs as their counterparts estimated from the OLS regression. Moreover, previously significant coefficients remained significant, and previously nonsignificant coefficients also stayed nonsignificant. However, compared to OLS estimates, the magnitude of most coefficients estimated from spatial lag regression decreased in absolute values to the extent their explanatory power was not due to their incounty values but to the neighboring locations that had been picked up by the spatially autoregressive coefficient in the current model specification. It is also noteworthy that the cases selected based on spatial lag regression were not identical to those selected based on OLS regression (see the remainder of this paper for the selection strategy), although the difference was minute.

In view of the fact that spatial analyses are for the most part predicated on the choice of spatial weights (Baller et al. 2001), we repeated the same analytical procedure with other spatial weights matrices, including a queen-based matrix that defined as neighbors any locations sharing either a border or a vertex in their boundaries, and a distance-based matrix that defined as neighbors any locations within so many miles, kilometers, feet, etc. It turned out that the results associated with different spatial weights matrices were quite similar to one another. We then decided to report the parameter estimates derived from the queen-based spatial weights matrix in the following section. 


\subsection{Model Results}

As shown in Table 2, the first block model indicated that the rate of working poor in 1990 significantly explained large amount of the variance in the rate of working poor in $2000\left(\mathrm{R}^{2}\right.$ change $=78$ percent -18 percent $=60$ percent $)$ since the spatial autoregressive term alone could only account for less than 18 percent of the variance in the same dependent variable. ${ }^{3}$ This implies a great deal of stability in the dependent variable over the ten-year period, even adjusted for the spatial dependence/autocorrelation. To a large extent, counties with high/low rates of working poor in 1990 remained high/low in 2000 . The second block model (see Model 2) indicated that the level of rurality of a county in 1990 had a significantly negative effect $(\beta=-0.154, p<.001)$ on change in the rate of working poor during the 1990-2000 period. That is, counties that were more rural in 1990 tended to experience declines in the rate of the working poor rate over the subsequent decade. The effect of rurality remained significant and negative in Model 3 ( $\beta=-0.166$, $p<.001$ ), which controlled for employment mix by industry. But when we added labor force characteristics and household demographic variables, the significance of rurality disappeared as shown in Model 4. This indicated that the differences in labor force and demographic characteristics of highly rural counties compared to less rural nonmetropolitan counties and metropolitan counties are more important in explaining change in the rate of working poor than being in a remote location per se.

In the third block model (see Model 3), a significant, negative effect was found for the percent of people employed in construction in $1990(\beta=-0.143, p<.01)$, while significant, positive effects were found for the percent of people employed in 1990 in government $(\beta=0.083, p<.001)$, service $(\beta=0.071, p<.01)$, manufacturing $(\beta=0.034$, $p>.05)$, and agriculture/mining $(\beta=0.030, p<.05)$. In other words, having a greater percentage employed in construction led to a decrease in the rate of working poor (construction jobs pay higher wages), while having a greater percentage employed in government, service, manufacturing, and agriculture/mining jobs was associated with an increase in the rate of working poor. The findings for agriculture jobs reflect broader macroeconomic trends mentioned earlier, including the fact that current farm labor needs are primarily met by hiring part-time, seasonal workers. In terms of service, our findings support the idea that the vast majority of these jobs are service provisional jobs that pay lower wages, and many are contingent (e.g., retail sales, fast food service). We are intrigued by the finding that increased manufacturing and government employment (state and federal) led to an increase in the rate of working poor. One explanation is that the greater dependence on government and/or manufacturing employment at the beginning of the decade contributed to growth in low-wage, social service jobs, or was associated with the growth of low-wage jobs in other sectors of the local economy. Specific to government, it is possible that these jobs, particularly at the state and local level, largely involve either providing a social safety net for the working poor or producing public

${ }^{3}$ Standardized coefficients are presented in Appendix 1; collinearity diagnostics appear in Appendix 2. 
TABLE 2

Lagged Effects Model of Rurality, Industry, and Demographics on the 2000 Rate of Working Poor for Counties in the North Central Region $(\mathrm{N}=1055)$, Unstandardized Coefficients, Adjusted for Spatial Autocorrelation

\begin{tabular}{|c|c|c|c|c|}
\hline \multirow{2}{*}{$\begin{array}{c}\text { Independent } \\
\text { Variables }\end{array}$} & \multicolumn{4}{|c|}{ Unstandardized Regression Coefficients } \\
\hline & Model 1 & Model 2 & Model 3 & Model 4 \\
\hline Constant & .053 & .301 & $-2.348^{*}$ & $-5.301^{*}$ \\
\hline Spatial Lag & $.061^{*}$ & $.118^{* * *}$ & $.137^{* * *}$ & $.177^{* * *}$ \\
\hline \%Poverty90 & $.764^{* * *}$ & $.778^{* * *}$ & $.694^{* * *}$ & $.549^{* * *}$ \\
\hline Rurality & & $-.154^{* * *}$ & $-.166^{* * *}$ & -.033 \\
\hline \multicolumn{5}{|l|}{ Employment Mix by Industry } \\
\hline$\% A g / M i n i n g$ & & & $.030^{*}$ & $.086^{* * *}$ \\
\hline$\%$ Manufacture & & & $.034^{*}$ & $.034^{*}$ \\
\hline \%Construction & & & $-.143^{* *}$ & -.006 \\
\hline$\%$ Service & & & $.071^{* *}$ & $.066^{* *}$ \\
\hline \%Government & & & $.083^{* * *}$ & $.063^{* * *}$ \\
\hline \multicolumn{5}{|c|}{ Labor Force and Demographic Composition } \\
\hline$\%$ Female Labor & & & & $-.117^{* *}$ \\
\hline \%Nonwhite Labor & & & & .010 \\
\hline$\%$ Young Labor & & & & $.210^{* * *}$ \\
\hline \%Elderly Labor & & & & $.090^{*}$ \\
\hline$\%$ Female Head of Household & & & & $.178^{* * * *}$ \\
\hline \%Elderly Head of Household & & & & $-.065^{* *}$ \\
\hline$\%$ College Labor & & & & -.007 \\
\hline $\mathbf{R}^{2}$ & .778 & .784 & .800 & .822 \\
\hline
\end{tabular}

goods used by the working poor (such as public transportation). In terms of manufacturing, however, the interpretation is less apparent and reflects the uneven impacts of globalization. Increased working poor in areas with high percentages of manufacturing could be the result of rural growth in which communities have successfully preserved or attracted new manufacturing industry, either from urban decentralization or foreign investment. The lack of clear understanding despite the validity of our model lends support for further exploration though the coordinated case study effort proposed by our mixed methods research design.

The fourth block model (see Model 4) adds the labor force and demographic measures. This model explains the greatest amount of variation in the change in the rate of 
working poor rate $\left(\mathrm{R} 2=82\right.$ percent). ${ }^{4}$ As noted previously, the effects of rurality are no longer significant in this model. Additionally, the effect of percent employment in construction becomes insignificant after controlling for county-level demographic characteristics in 1990. The percent of employment in government and manufacturing industries in 1990 still has significant, positive effects $(\beta=0.063, p<.001)$ and $(\beta=0.034, p<.05)$, respectively, as does the percent employment in agriculture/mining in $1990(\beta=0.086$, $p<.001)$ and service in $1990(\beta=0.066, p<.01)$. These latter findings indicate that counties within the region with a greater dependence on extractive, manufacturing, government, and service industries at the beginning of the decade tended to experience increases in the rate of working poor over the course of 1990-2000 period. This issue will also be examined in more detail in the case studies (Loveridge et al. 2007).

In examining the effects of the demographic variables, we found that the 1990 percent of labor force between 16-24 years of age $(\beta=0.210, p<.001)$, the 1990 percent of elderly labor force 55 years and over, $(\beta=0.090, p<.05)$, and the 1990 percent of female-headed households $(\beta=0.178, p<.001)$ had significant, positive relationships with change in the rate of working poor. Thus, counties within the North Central region with higher percentages of these demographic groups at the beginning of the decade tended to experience increases in the rate of working poor over the 1990-2000 period. These findings reaffirm the importance of the age structure of the labor force and the gender of household heads as "supply-side" factors influencing the prevalence of working poor.

Interestingly, the 1990 percent of households headed by elderly persons 65 years and over $(\beta=-0.065, p<.01)$ and the 1990 percent of the labor force that was female $(\beta=-0.117, p<.01)$ were found to have a significant and negative relationship with change in the rate of working poor (see Model 4). These findings appear contradictory; that is, counties with a larger percentage of elderly-headed households in 1990 experienced a decrease in the rate of working poor while those with a higher percentage of elderly in the labor force experienced increases in the rate of working poor. One potential interpretation is that when elderly people work, it is because they need the income and

\footnotetext{
${ }^{4}$ The diagnostics for multicollinearity revealed several independent variables with substantial variance inflation factor (VIF) coefficients (see Appendix 2). These coefficients indicated strong interrelationships between percent employed in agriculture, percent of the labor force 55 years and over, percent households headed by persons 65 years and over, and to a lesser extent percent employed in manufacturing and percent employed in services. While this represents a greaterthan-optimal level of multicollinearity, it is important to note that this problem did not inflate the standard error estimates to the extent that the t-tests were insignificant for any of these independent variables. Each of these independent variables was theoretically conceived as a distinct feature of local labor market or demographic structures that influence the local prevalence of working poor. This seems to be a reasonable assumption, particularly given that there is no substantive commonality underlying these variables to suggest that they are highly correlated because they all measure a latent theoretical construct. Since the exclusion of any of these variables would produce highly biased estimates for those variables that are included, it was decided to retain estimates that were unbiased in exchange for less efficient ones.
} 
are more likely to accept work in low-wage occupations. Elderly-headed households, however, may or may not have household members in the labor force. Many of these households may be living comfortably on retirement savings and other income sources. Conversely, it is not the prevalence of women in the labor force per se that contributes to the growth of the working poor. Rather, it is the presence of female-headed households that tend to lack income from other sources, are urgently in need of employment, and more likely to accept low-wage jobs.

\subsection{Case Selection for Systematic Cross-Case Analysis}

Overall, the independent variables specified in the panel models accounted for a substantial proportion of the variation in change in the rate of working poor across the counties in the North Central region. As a result of this strong goodness-of-fit, the fully specified panel model (see Model 4, Table 2) was used in the selection of case study sites where development processes affecting the working poor can be studied in more detail in order to identify policies and social processes that work to ameliorate the prevalence of the working poor population as well as policies and processes that serve to promote its growth. Based on the regression findings and the amount of change in the rate of working poor, two subsets of counties within the region were identified.

1. Counties at or above the eightieth percentile of the first-order difference in the rate of working poor (2000 rate minus 1990 rate) and located at or above the eightieth percentile in distribution of residuals from the regression model. These counties not only had the highest increases in working poor rates within the North Central region during the 1990-2000 period, but also had much higher increases than expected based on their labor market attributes, demographic characteristics, and spatial context.

2. Counties at or below the twentieth percentile of the first-order difference in the rate of working poor and located at or below the twentieth percentile in the distribution of residuals from the regression model. These counties not only had the largest decreases in rates of working poor within the North Central region, but also had much larger decreases than expected based on their spatial location, labor market attributes and demographic characteristics.

In effect, these two subsets of counties represent the extremes in the spatial distribution of the working poor within the region. Because we are interested in the nonmetropolitan working poor, we deselected metro counties based on the 2003 Rural-Urban Continuum Code (Economic Research Service, 2003). Based on these criteria, 112 counties were identified in the first subset while 126 counties were identified in the second subset. Case studies of the former subset will identify policies and social processes that serve to promote and exacerbate work-based poverty. Case studies of the latter will identify policies and processes that help to reduce work-based poverty and potentially could serve as models for other nonmetropolitan areas. The final step of our sequential explanatory 


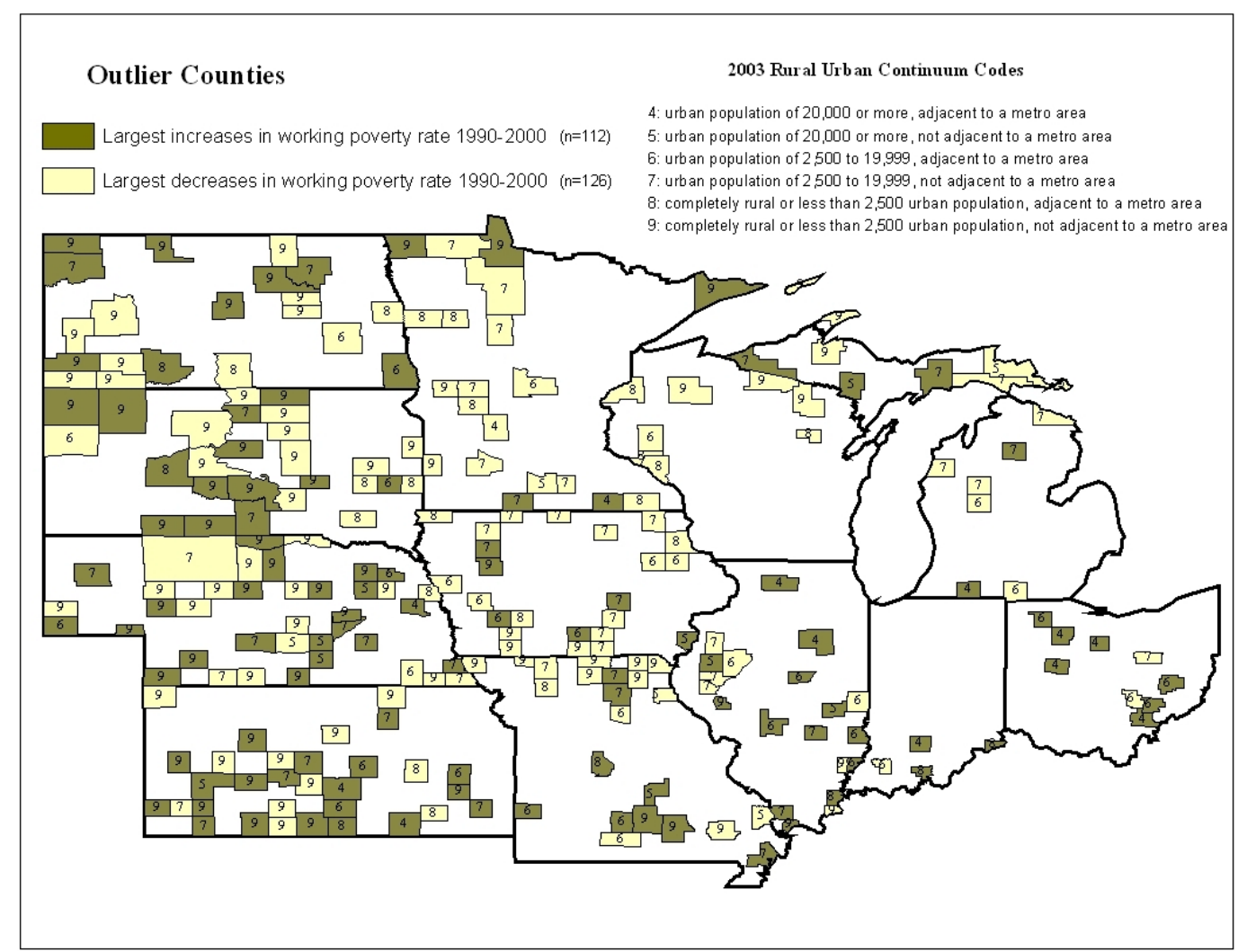

FIGURE 3. Case Selection, North Central Counties $(\mathrm{N}=238)$

design calls for a coordinated effort among scholars within the region to determine the nature of the policies and development strategies employed by local community actors that affected change in the working poor. The outliers and unexplained variance from our economic model lends itself to systematic selection and analysis of qualitative comparative case studies. The article by Loveridge et al. (2007) undertakes this task by focusing on outliers, or the places that do not conform to established patterns of development. By selecting counties from our model, the cases are uniquely coordinated in the sense that they do not fit the model well, indicating that there may be systematic areas of difference missed by econometric analysis.

\section{CONCLUSION}

In this paper, we presented a model of changing rates of working poor that demonstrated the importance of consideration to spatial inequality. We then offered a research tool - sequential explanatory design - to address the question of why some counties have greater than and less than average rates of change in working poor. We demonstrated a method of systematically selecting cases based on findings from our econometric model. 
Our work, in coordination with the case study results presented by Loveridge et al. (2007), demonstrates the strength of mixed method research designs.

Our study advances research in the regional and social sciences by proposing a mixed method tool for coordinating cases to further explore spatial inequality across regions. By integrating our findings with the results from Loveridge et al. (2007), the relationship between structural constraints facing the working poor and agency-driven opportunities that promote quality of life for members of nonmetropolitan communities are more deeply explicated. Given recent changes in federal government programs, as well as the continuing impacts of global economic restructuring, such knowledge is essential for the long-term viability of nonmetropolitan communities. Collectively, our research outcomes will advance social sciences by improving our appreciation of nonmetropolitan communities challenged by increased numbers of working poor. We expect our results to have a significant positive impact on the social and economic well-being of nonmetropolitan communities in the United States, helping to sustain and enrich them. Identification of outliers provides researchers with an underutilized benchmark in policy assessment. Our mixed method tool provides what Hooks, Lobao, and Tickamyer (2007, p. 258) refer to as a "systematic conceptual template that can be used to study both the distribution of inequality and the social forces creating uneven development at different scales." To this end, we hope our research will contribute to a more comprehensive effort by scholars to understand changing rates of working poor by using mixed methods research, as well as help policy makers, regional scientists, rural sociologists, and community leaders better understand the social implications of working poor in nonmetropolitan communities.

\section{REFERENCES}

Anderson, C.D., M.D. Schulman, and P.J. Wood, 2001. "Globalization and Uncertainty: The Restructuring of Southern Textiles," Social Problems 48(4), 478-498.

Anderson, C.D. and C.Y. Weng, 2006a. "Growth in the Working Poor: A Cross Sectional Model of the Rural Counties in the Central United States," paper presented at the annual meetings of the North American Meetings of the Regional Science Association International, Toronto, Canada.

, 2006b. "The Working Poor in the Midwest," paper presented at the annual meetings of the Midwest Sociological Society, Omaha, NE.

Anselin, L., 1988. Spatial Econometrics: Methods and Models. Kluwer Academic: Boston.

, 2001. "Spatial Effects in Econometric Practice in Environmental and Resource Economics," American Journal of Agricultural Economics 83, 705-710. , 2005. Exploring Spatial Data with GeoDa: A Workbook. Spatial Analysis Laboratory (SAL), Department of Agricultural and Consumer Economics, University of Illinois: Urbana-Champaign, IL.

Anselin, L. and A.K. Bera, 1998. "Spatial Dependence in Linear Regression Models with an Introduction to Spatial Econometrics," in A. Ullah and D.E.A. Giles (eds.), Handbook of Applied Economic Statistics. Marcel Dekker: New York. 
Anselin, L., I. Syabri, and Y. Kho, 2004. Geoda: An Introduction to Spatial Data Analysis, Spatial Analysis Laboratory (SAL), Department of Agricultural and Consumer Economics, University of Illinois: Urbana-Champaign, IL.

Baller, R.D., L. Anselin, S.F. Messner, G. Deane, and D.F. Hawkins, 2001. "Structural Covariates of U.S. County Homicide Rates: Incorporating Spatial Effects," Criminology 39, 561-590.

Barrett, J., 2007. "How Ethanol Is Making the Farm Belt Thirsty," The Wall Street Journal (September 5), B1.

Becker, G.S., 1964. Human Capital: A Theoretical and Empirical Analysis, With Special Reference to Education. National Bureau of Economic Research: New York.

Blau, P.M. and O.D. Duncan, 1967. The American Occupational Structure. John Wiley \& Sons: New York.

Bluestone, B. and B. Harrison, 1982. The Deindustrialization of America. Basic: New York.

Coleman, J.S., 1993. "Social Capital in the Creation of Human Capital," American Journal of Sociology 94, S95-S120.

Creswell, J.W. and V.L. Plano Clark, 2007. Designing and Conducting Mixed Methods Research. Sage Publications: Thousand Oaks, CA.

Creswell, J.W., V.L. Plano Clark, M.L. Gutmann, and W.E. Hanson, 2002. "Advanced Mixed Methods Research Designs," in A. Tashakkori and C.B. Teddlie (eds.), The Handbook of Mixed Methods in Social and Behavioral Research. Sage Publications: Thousand Oaks, CA.

Dewees, S., L. Lobao, and L. Swanson, 2003. "Local Economic Development in an Age of Devolution," Rural Sociology 68(2), 186-206.

Economic Research Services, 2003. Rural-Urban Continuum Codes. www.ers.usda.gov/ Data/RuralUrbanContinuumCodes/counties>

Falk, W. and L. Lobao, 2003. "Who Benefits From Economic Restructuring?" in D. Brown and L. Swanson (eds.), Challenges for Rural American in the Twenty First Century. The Pennsylvania State University Press: State College PA.

Falk, W., M.D. Schulman, and A.R. Tickamyer, 2003. Communities of Work: Rural Restructuring in Local and Global Contexts. Ohio University Press: Athens, OH.

Gibbs, R. and T. Parker, 2001. "Rural Low Wage Employment Rises Among Men," Rural Conditions and Trends 11(2), 9-17.

Gibbs, R., L. Kusmin, and J. Cromartie, 2005. "Low-Skill Employment and the Changing Economy of Rural America," Economic Research Report No. (ERR10), www.ers. usda.gov/publications/err10/>.

Goe, W.R. and J.L. Shanahan, 1991. "Patterns of Economic Restructuring in IndustrialBased Metropolitan Areas," Urban Studies 28(4), 559-576.

Goe, W.R. and A. Rhea, 2000. "The Spatial Shift in the Growth of Poverty Among Families Headed by Employed Females, 1979-1989," Journal of Sociology and Social Welfare XXVII(2), 79-95.

Granovetter, M., 1973. "The Strength of Weak Ties," American Journal of Sociology 78, 1360-1380.

Hooks, G., L. Lobao, A. Tickamyer, 2007. "Conclusion: An Agenda for Moving a Spatial Sociology Forward," in L. Lobao, G. Hooks, and A. Tickamyer (eds.), Spaces, Places 
and Inequality: The Sociology of Spatial Inequality. The State University of New York Press: Albany.

Jensen, L. and T. Slack, 2002. "Underemployment in American: Measurement and Evidence," American Journal of Community Psychology 32(1/2), 21-31.

Kandel, W., 2006. "Meat Processing Firms Attract Hispanic Workers to Rural America," Amber Waves (June) www.ers.usda.gov/AmberWaves/June06/Features/MeatProcessing.htm.

Kenney, M., L. Lobao, J. Curry, and W.R. Goe, 1989. "Midwestern Agriculture in U.S. Fordism: From the New Deal to Economic Restructuring," Sociologia Ruralis XXIX (2), 131-148.

Land, K.C. and G. Deane, 1992. "On the Large-Sample Estimation of Regression Models with Spatial Effects Terms: A Two-Stage Least Squares Approach," Sociological Methodology 22, 221-248.

Lobao, L.M., L.A. Brown, and J. Moore, 2003. "Old Industrial Regions and the Political Economy of Development: The Ohio River Valley," in W.W. Falk, M.D. Schulman, and A.R. Tickamyer (eds.), Communities of Work: Rural Restructuring in Local and Global Contexts. Ohio University Press: Athens, $\mathrm{OH}$.

Lobao, L.M. and G. Hooks, 2003. "Public Employment, Social Welfare and Local WellBeing," Social Forces 81, 519-556.

Lobao, L., G. Hooks, and A. Tickamyer, 2007. "Introduction: Advancing the Sociology of Spatial Inequality," in L. Lobao, G. Hooks, and A. Tickamyer (eds.), Spaces, Places and Inequality: The Sociology of Spatial Inequality. The State University of New York Press: Albany.

Loveridge, S., L. Lobao, R. Goe, P. Thomas, N.A. Bradshaw, W.T. Brooks, D.J. Hess, and M.W. McCurry, 2007. "Advances and Declines in the Rural Working Poor: Complementing Traditional Econometric Results with Case Analysis," The Review of Regional Studies 37(3), 392-410.

Morse, J.M., 1991. "Approaches to Qualitative-Quantitative Methodological Triangulation," Nursing Research 40, 120-123. , 2002. "Principles of Mixed Methods and Multimethod Research Design," in A. Tashakkori and C.B. Teddlie (eds.), The Handbook of Mixed Methods in Social and Behavioral Research. Sage Publications: Thousand Oaks, CA.

Page, B. and R. Walker, 1991. "From Settlement to Fordism: The Agro-Industrial Revolution in the American Midwest," Economic Geography 67(4), 281-315.

Pfeffer, M.J., 1983. "Social Origins of Three Systems of Farm Production in the United States," Rural Sociology 48 (4), 540-562.

Portes, A. and J. Sensenbrenner, 1993. "Embeddedness and Immigration: Notes on the Social Determinants of Economic Action," American Journal of Sociology 98, 13201350.

Putnam, R.D., 2000. Bowling Alone: The Collapse and Revival of American Community. Simon \& Schuster: New York.

Rank, M.R., 2004. One Nation, Underprivileged: Why American Poverty Affects Us All. Oxford University Press: New York.

Schulman, M.D. and C. Anderson, 1999. "The Dark Side of the Force: A Case Study of Restructuring and Social Capital,” Rural Sociology 64, 351-372. 
Scott, A.J., 1988. Metropolis: From Division of Labor to Urban Form. University of California Press: Los Angeles.

Summers, G.F., 1976. Industrial Invasion of Non-Metropolitan America. Praeger: New York.

United States Department of Labor, Bureau of Labor Statistics, 2002. "A Profile of the Working Poor, 2000," Report 957. www.bls.gov/cps/cpswp2000.htm, accessed September 24, 2007.

Walzer, N., 2003. The American Midwest: Managing Change in Rural Transition. M.E. Sharp: Armonk, NY.

Woolcock, M., 1998. "Social Capital and Economic Development: Toward a Theoretical Synthesis and Policy Framework," Theory \& Society 27, 151-208.

\section{APPENDIX 1}

Lagged Effects Model of Rurality, Industry and Demographics on the 2000 Rate of Working Poor for Counties in the North Central Region $(\mathrm{N}=1055)$, Standardized Coefficients Adjusted for Spatial Autocorrelation

\begin{tabular}{|c|c|c|c|c|}
\hline \multirow{2}{*}{$\begin{array}{c}\text { Independent } \\
\text { Variables }\end{array}$} & \multicolumn{4}{|c|}{ Standardized Regression Coefficients } \\
\hline & Model 1 & Model 2 & Model 3 & Model 4 \\
\hline Spatial Lag & $.038^{*}$ & $.074^{* * *}$ & $.086^{* * * *}$ & $.111^{* * * *}$ \\
\hline \%Poverty90 & $.864^{* * *}$ & $.881^{* * *}$ & $.786^{* * *}$ & $.622^{* * *}$ \\
\hline Rurality & & $-.093^{* * *}$ & $-.101^{* * *}$ & -.020 \\
\hline \multicolumn{5}{|l|}{ Employment Mix by Industry } \\
\hline$\% \mathrm{Ag} /$ Mining & & & $.076^{*}$ & $.215^{* * *}$ \\
\hline$\%$ Manufacture & & & $.079^{*}$ & $.078^{*}$ \\
\hline$\%$ Construction & & & $-.053^{* *}$ & -.002 \\
\hline$\%$ Service & & & $.087^{* *}$ & $.080^{* *}$ \\
\hline \%Government & & & $.116^{* * *}$ & $.087^{* * *}$ \\
\hline \multicolumn{5}{|c|}{ Labor Force and Demographic Composition } \\
\hline$\%$ Female Labor & & & & $-.060^{* *}$ \\
\hline \%Nonwhite Labor & & & & .018 \\
\hline$\%$ Young Labor & & & & $204^{* * *}$ \\
\hline \%Elderly Labor & & & & $.096^{*}$ \\
\hline$\%$ Female Head of Household & & & & $.175^{* * *}$ \\
\hline \%Elderly Head of Household & & & & $-.097^{* * *}$ \\
\hline \%College Labor & & & & -.008 \\
\hline $\mathbf{R}^{2}$ & .778 & .784 & .800 & .822 \\
\hline
\end{tabular}




\section{APPENDIX 2}

Collinearity Diagnostics for Lagged Effects Model of Rurality, Industry, and Demographics on the 2000 Rate of Working Poor for Counties in the North Central Region $(\mathrm{N}=1055)$, Adjusted for Spatial Autocorrelation

\begin{tabular}{|c|c|c|c|c|c|c|c|c|}
\hline \multirow{3}{*}{$\begin{array}{l}\text { Independent } \\
\text { Variables }\end{array}$} & \multicolumn{8}{|c|}{ Colinearity Diagnostics } \\
\hline & \multicolumn{2}{|c|}{ Model 1} & \multicolumn{2}{|c|}{ Model 2} & \multicolumn{2}{|c|}{ Model 3} & \multicolumn{2}{|c|}{ Model 4} \\
\hline & Tolerance & VIF & Tolerance & VIF & Tolerance & VIF & Tolerance & VIF \\
\hline Spatial Lag & .807 & 1.239 & .700 & 1.429 & .647 & 1.545 & .593 & 1.685 \\
\hline \%Poverty90 & .807 & 1.239 & .782 & 1.278 & .519 & 1.927 & .272 & 3.678 \\
\hline Rurality & & & .766 & 1.305 & .457 & 2.187 & .299 & 3.348 \\
\hline \multicolumn{9}{|l|}{ Industry } \\
\hline$\% \mathrm{Ag} / \mathrm{Mining}$ & & & & & .154 & 6.474 & .088 & 11.422 \\
\hline$\%$ Manufacture & & & & & .180 & 5.566 & .168 & 5.951 \\
\hline$\%$ Construction & & & & & .733 & 1.364 & .610 & 1.638 \\
\hline$\%$ Service & & & & & 261 & 3.833 & 211 & 4.747 \\
\hline$\%$ Government & & & & & .451 & 2.217 & .347 & 2.885 \\
\hline \multicolumn{9}{|l|}{ Demographic Composition } \\
\hline \%Female Labor & & & & & & & .426 & 2.349 \\
\hline \%Nonwhite Labor & & & & & & & .398 & 2.514 \\
\hline \%Young Labor & & & & & & & .238 & 4.203 \\
\hline \%Elderly Labor & & & & & & & .117 & 8.523 \\
\hline$\%$ Female Head of Household & & & & & & & .301 & 3.319 \\
\hline$\%$ Elderly Head of Household & & & & & & & .144 & 6.941 \\
\hline \%College Labor & & & & & & & .371 & 2.695 \\
\hline $\mathbf{R}^{2}$ & .778 & & .78 & & .80 & & & \\
\hline
\end{tabular}

